\title{
Energetics of Growth of Azotobacter vinelandii in a Glucose-limited Chemostat Culture
}

\author{
By S. NAGAI, Y. NISHIZAWA AND S. AIBA \\ Institute of Applied Microbiology, University of Tokyo, Tokyo, Japan
}

(Accepted for publication 20 August 1969)

\begin{abstract}
SUMMARY
With a glucose-limited chemostat culture of Azotobacter vinelandii IAM 1078 the yield factor, $Y \frac{X}{S}$, for glucose increased from 0.3 to 0.12 following an increase in the dilution rate from 0.1 to $0.35 \mathrm{hr}^{-1}$. However, even when growing at the faster rate the value of $Y_{\bar{S}}^{X}$ still was extremely small compared to those found with other micro-organisms. This low yield value was not due to an incomplete oxidation of glucose, since most of the glucose carbon utilized $(83$ to $97 \%$ ) could be accounted for as carbon dioxide, the percentage conversion depending on the dilution rate. The specific respiration rate $\left(Q_{\mathrm{O}_{2}}\right)$ of the growing culture was determined in situ and found to remain nearly constant over the range of dilution rates. However, the value of $Y_{\bar{S}}^{\underline{X}}$ diminished progressively from 0.12 to 0.03 when the dissolved oxygen concentration in a chemostat culture was increased from 3.3 to 5.7 p.p.m. The yield factor, $Y_{\mathrm{ATP}}$ (evaluated by making certain assumptions) was much smaller than the value of 10 found with other microbial culture, even though the value of $Y_{\mathrm{ATP}}$ increased appreciably with the increase of dilution rate. These results are discussed with reference to some of the known physiological characteristics of $A$. vinelandii.
\end{abstract}

\section{INTRODUCTION}

With several species of bacteria, a linear relationship has been found between the reciprocal of the overall yield factor $Y_{S}^{X}$ and the reciprocal of the specific growth rate $\mu_{X}$ (Pirt, 1965). Similarly, a glucose-limited chemostat culture of Azotobacter vinelandii (dilution rate $=0.1$ to $0.25 \mathrm{hr}^{-1}$ ) showed the same general pattern (Aiba, Nagai, Nishizawa \& Onodera, I967). In order to understand the physiological implications of this variation in $Y_{\bar{S}}$ with growth rate, we have examined the effects of varying the dilution rate on the fate of the glucose substrate.

With various microbial cultures, many workers have observed an 'ATP-yield value' ( $Y_{\mathrm{ATP}}=\mathrm{mg}$. bacteria synthesized/mmole ATP consumed) of about Io (see Bauchop \& Elsden, 1960; Stouthamer, I962; Hadjipetrou et al. 1964). But since all these workers grew their organisms in uncontrolled environments (i.e. batch cultures) the influence of specific nutritional conditions, as realized in a chemostat culture, remained to be investigated. The effect of growth rate on the $Y_{\text {ATP }}$ value of a glucose-limited culture of Azotobacter vinelandii is also reported here. 


\section{METHODS}

Organism and cultural conditions. The bacterium used was Azotobacter vinelandii IAM 1078 (ATCC 9046). The medium composition was (g./1.): glucose, $5 ; \mathrm{KH}_{2} \mathrm{PO}_{4}, 0.2$; $\mathrm{K}_{2} \mathrm{HPO}_{4}, 0.8 ; \mathrm{MgSO}_{4} .7 \mathrm{H}_{2} \mathrm{O}, 0.2 ; \mathrm{NaCl}, 0.2$; sodium citrate, $0.05 ; \mathrm{FeSO}_{4} .7 \mathrm{H}_{2} \mathrm{O}$, $0.005 ; \mathrm{Fe}_{2}\left(\mathrm{SO}_{4}\right)_{3} \cdot 3 \mathrm{H}_{2} \mathrm{O}, 0.005 ; \mathrm{Na}_{2} \mathrm{MoO}_{4} .2 \mathrm{H}_{2} \mathrm{O}$, 0.00I; $\mathrm{CaCl}_{2} .2 \mathrm{H}_{2} \mathrm{O}, 0.0 \mathrm{I} ; \mathrm{pH} 7.0-$ $7 \cdot 2$. It was confirmed by preliminary experiments that sodium citrate in the medium did not serve as a carbon source; glucose was the sole utilizable carbon source.

The reactor vessel (working volume $=13-181$, , nominal volume $=291$.) was equipped with a standard flat-blade turbine ( 780 r.p.m.). The aeration from a ring sparger below the impeller was kept at 0.5 to I.5 v.v.m. Each continuous culture run (dilution rate $=0.05-0.35 \mathrm{hr}^{-1}$ ) was assumed to be in a steady state if the optical density value (at $6 \operatorname{Io} \mathrm{m} \mu$ ) for the culture remained unchanged for about $24 \mathrm{hr}$. The residual glucose concentration in the effluent from the vessel was of the order of $2 \mu \mathrm{g} . / \mathrm{ml}$. The reactor was run at $30^{\circ} \pm 0.5^{\circ}$.

Determination of cell mass and glucose concentration. Bacterial mass was measured as a freeze-dried powder (Aiba et al. 1967). Water content of this material was around I $5 \%$. Residual glucose was measured either by the method of Somogyi (I952) or with a Glucostat reagent (Worthington Biochemical Corporation).

Measurement of the oxygen uptake rate. Aeration rate was carefully controlled to determine the oxygen uptake of bacteria in the chemostat. A reducing valve and a rotameter were installed on the air line. Oxygen in the air flow, before entering and after leaving the chemostat, was determined using a Beckman oxygen electrode (Beckman-Toshiba Type 777).

Measurement of rate of carbon dioxide evolution. Water, 5.51 ., in a conical flask was replaced by the exhaust air from the chemostat. An aqueous solution (100 ml.) of $0 \cdot 2-\mathrm{N}$ barium hydroxide was then carefully added and the flask shaken mechanically for about $30 \mathrm{~min}$. After standing for $3 \mathrm{hr}$, the solution was back titrated with oxalic acid (O.I N) and the concentration of carbon dioxide in the exhaust air calculated from these data. The concentration of carbon dioxide in the ambient air was measured, as control, by the same procedure. The rate of carbon dioxide evolution in the chemostat was calculated from the difference in $\mathrm{CO}_{2}$ content between the ambient and exhaust air (duplicate measurement), and the air flow rate. Temperatures of the air entering and leaving the fermentor were measured and the rates of oxygen uptake and carbon dioxide evolution corrected to $0^{\circ}, \mathrm{I}$ atm.

\section{RESULTS}

Experimental data from a typical chemostat culture experiment are shown in Table I. Clearly the maximum dilution rate under these conditions was about $0.34 \mathrm{hr}^{-1}$. Since the glucose concentration in the extracellular fluid was insignificant compared with that of fresh medium $\left(S_{0}=5 \pm 0.2 \mathrm{mg} . / \mathrm{ml}\right.$. $)$, the value $Y \frac{X}{\bar{s}}$ could be determined merely from the concentration ratio of cultured bacterial mass to glucose in the input medium.

\section{Assimilation-dissimilation ratio of glucose}

The metabolic activities, as represented by the specific rates of glucose consumption, assimilation to cell carbon and dissimilation to $\mathrm{CO}_{2}$, are plotted against the dilution 
rate in Fig. I. An average of carbon content ( $45 \%$ ) determined by elemental analysis of the bacteria from the chemostat culture was used to assess the specific rate of the assimilation.

The recovery ratio, defined by the ratio of a sum of the assimilated and dissimilated carbon to the glucose carbon consumed, is also shown in this figure. Despite the data

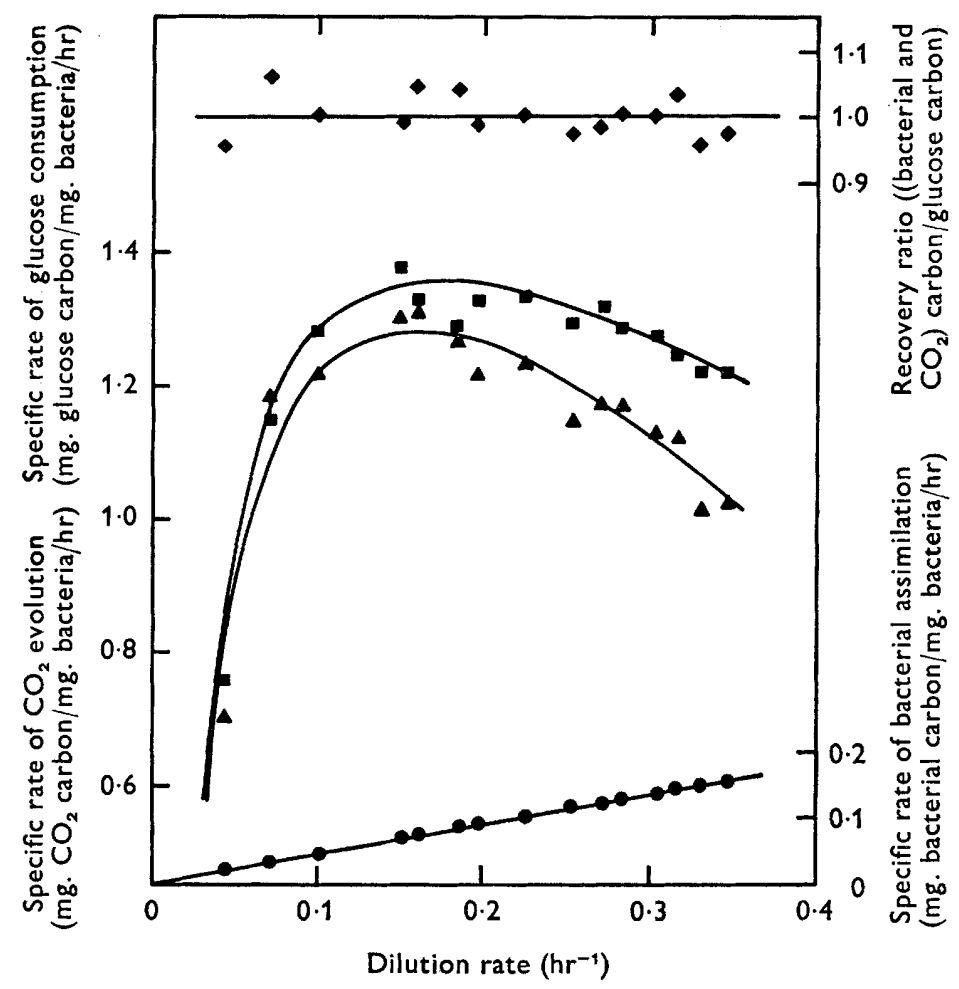

Fig. I. Specific rates (carbon basis) of cellular assimilation, $\mathrm{CO}_{2}$ evolution and glucose consumption of Azotobacter vinelandii as varied with dilution rate of glucose-limited chemostat culture. Glucose concentration in fresh medium, $S_{0}=5 \pm 0.2 \mathrm{mg} . / \mathrm{ml}$. - cellular assimilation; $\boldsymbol{\Delta}-\mathbf{\Delta}, \mathrm{CO}_{2}$ evolution; $\mathbf{-}-\mathbf{\square}$, glucose consumption; $-\boldsymbol{-}$, recovery ratio.

Table I. Bacterial mass and glucose concentrations in a glucose-limited chemostat culture of Azotobacter vinelandii

Glucose concentration in fresh medium $=5 \pm 0 \cdot 2(\mathrm{mg} / \mathrm{ml}$.); agitation speed $=780$ r.p.m.; aeration rate $=0.7 \sim 1.0$ v.v.m.

$\begin{array}{ccc}\begin{array}{c}\text { Dilution rate } \\ \left(\mathrm{hr}^{-1}\right)\end{array} & \begin{array}{c}\text { Bacterial mass } \\ \text { concentration } \\ (\mathrm{mg} . \text { cell } / \mathrm{ml} .)\end{array} & \begin{array}{c}\text { Glucose } \\ \text { concentration } \\ (\mu \mathrm{g} . \text { glucose/ml. })\end{array} \\ 0.100 & 0.150 & 0.8 \\ 0.149 & 0.192 & 1 \cdot 2 \\ 0.224 & 0.33 \mathrm{I} & 1 \cdot 0 \\ 0.253 & 0.384 & 2.0 \\ 0.304 & 0.470 & 1 \cdot 5 \\ 0.316 & 0.509 & 3.0 \\ 0.340 & 0.536 & 27.0\end{array}$


scattering, the recovery ratio was invariably nearly one. Therefore in this chemostat culture, Azotobacter vinelandii obviously produced no metabolites other than bacterial cells and carbon dioxide.

Experimental data of yield factor for glucose $\left(Y \frac{\mathbb{X}}{\bar{S}}\right)$, the ratio of assimilation to dissimilation $\left(\Delta X / \Delta \mathrm{CO}_{2}\right)$, and the ratio of dissimilation to glucose consumption $\left(\Delta \mathrm{CO}_{2} /-\Delta S\right)$ are shown in Fig. 2. Clearly growth of this micro-organism in a chemostat culture was characterized by a very small value of $Y_{\bar{S}}^{\underline{X}}$ compared with the data reported by other workers (for example, $Y_{\mathbb{S}}^{\mathbb{X}}$ is 0.5 for Aerobacter cloacae (Herbert,

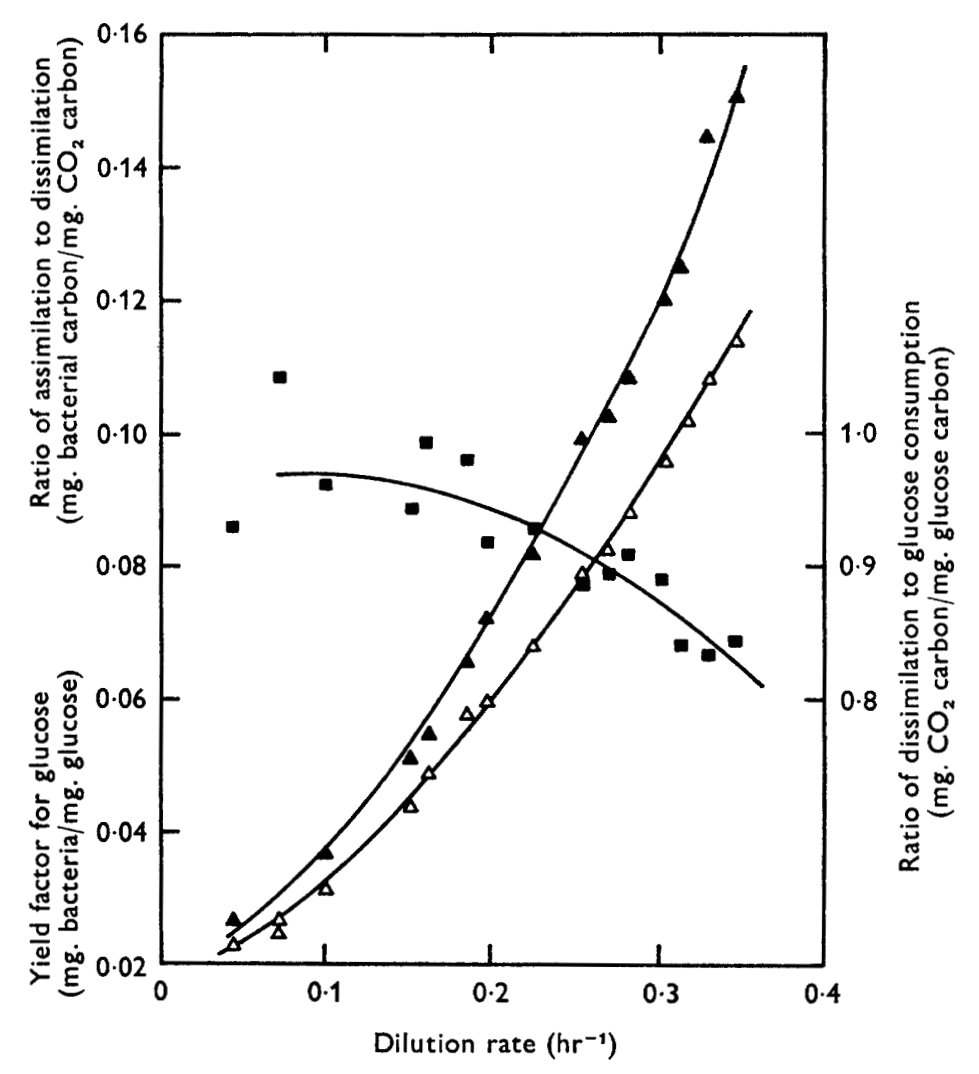

Fig. 2. Yield factor for glucose, ratio of assimilation to dissimilation and that of glucose consumption for Azotobacter vinelandii (glucose-limited chemostat culture). These ratios are on the carbon bases. $\Delta-\Delta$, yield factor for glucose; $-\mathbf{n}$, ratio of dissimilation to glucose consumption; $\Delta-\Delta$, , ratio of assimilation to dissimilation.

Elsworth \& Telling, 1956), Escherichia coli (Schulze \& Lipe, 1964) and Aerobacter aerogenes (Baidya, Webb \& Lilly, 1967), and 0.3 to 0.4 in Aerobacter cloacae (Pirt, I965) in carbohydrate-limited chemostat cultures). Furthermore, as this dilution was increased progressively, so $Y \frac{X}{\mathscr{S}}$ and $\Delta X / \Delta \mathrm{CO}_{2}$ increased appreciably and $\Delta \mathrm{CO}_{2} /-\Delta S$ diminished.

\section{Oxygen uptake rate}

The influence of dilution rate on the specific rate of oxygen uptake $\left(Q_{\mathrm{O}_{2}}\right)$, glucose consumption, the dissolved oxygen concentration and yield factor for oxygen $\left(Y_{\bar{o}}^{\frac{X}{\sigma}}\right)$ 
are plotted in Fig. 3. Values of the respiratory quotient (R.Q.) were approximately unity, and the specific rate of oxygen uptake was nearly $\mathrm{O} \cdot \mathrm{I} \mathrm{m}$-mole $\mathrm{O}_{2} / \mathrm{mg}$. bacterium $/ \mathrm{hr}$ ( $\simeq 2,000 \mu \mathrm{l} . \mathrm{O}_{2} / \mathrm{mg}$. bacterium $/ \mathrm{hr}$ ), irrespective of the dilution rate. This large $Q_{\mathrm{o}_{2}}$ value is in agreement with that published by Tissières, Hovenkamp \& Slater (I957) on the same species. Indeed, Azotobacter vinelandii is characterized by the large value of $Q_{\mathrm{o}_{2}}$.

The dissolved oxygen concentration decreased with an increase in dilution rate (see Fig. 3), whereas the values of $Y \frac{X}{o}$ increased appreciably. The same trend was

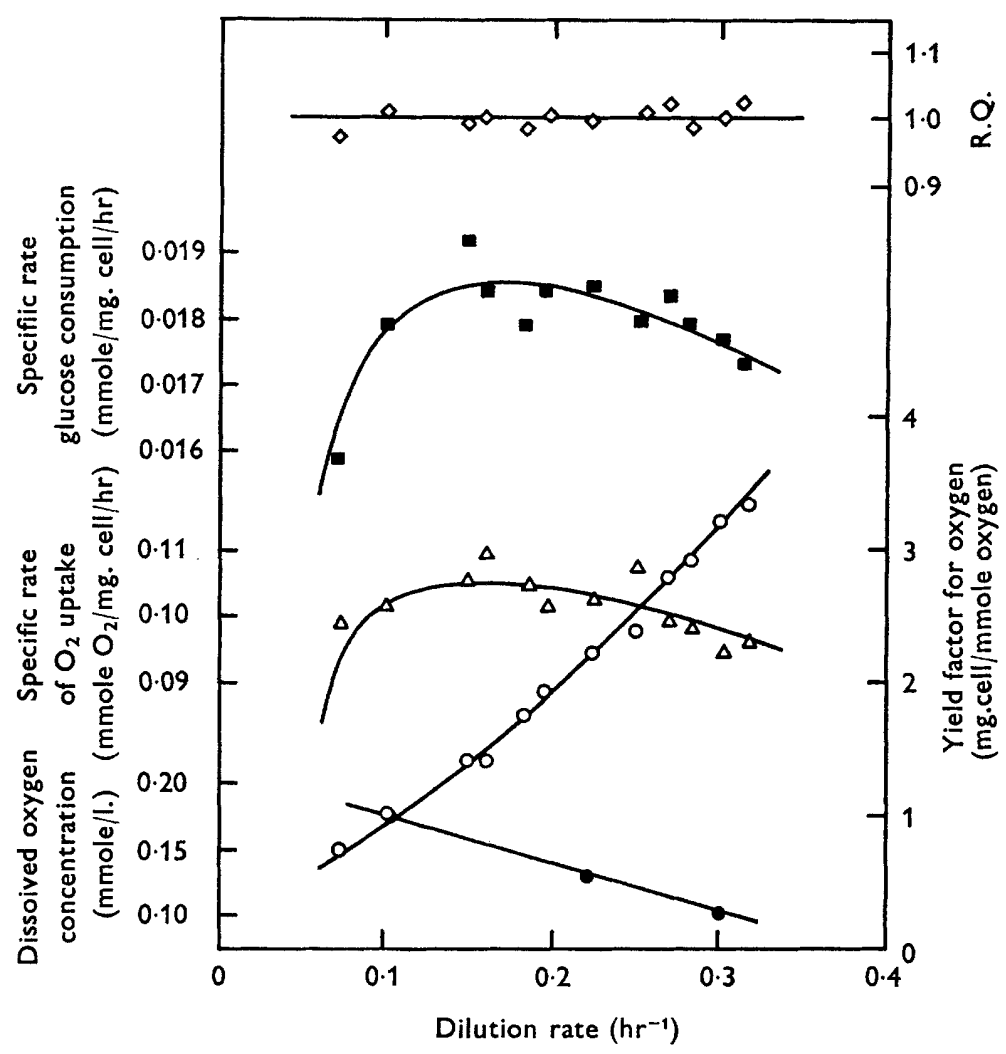

Fig. 3. Yield factor for oxygen, specific rate of $\mathrm{O}_{2}$ uptake and dissolved oxygen concentration in glucose-limited chemostat culture of Azotobacter vinelandii. Specific rate of glucose consumption reproduced from Fig. I and R.Q. values are included. Specific rate in glucose-carbon basis formerly is converted here to molar unit. R.Q. values are duly calculated referring to Fig. I. Dissolved oxygen concentration is measured at agitation speed $=780$ r.p.m. and aeration rate $=0.6$ v.v.m. $O-O$, yield factor for oxygen; $\triangle-\triangle$, specific rate of $\mathrm{O}_{2}$ uptake; $-\square$, dissolved oxygen concentration; $\mathbf{\square}-\mathbf{\square}$, specific rate of glucose consumption; $\diamond-\diamond$, respiratory quotient, R.Q.

apparent between $Y_{\bar{S}}^{\underline{X}}$ (see Fig. 2) and dissolved oxygen. This fact suggests the possibility that high levels of dissolved oxygen inhibit the cell synthesis and energy metabolism. In this connection, Parker \& Scutt (1960) found an inhibitory effect of oxygen on the growth of Azotobacter. 


\section{DISCUSSION}

$Y_{\mathrm{ATP}}$, defined by the ratio of the bacterial mass synthesis to ATP, can be represented by the following equation,

$$
Y_{\mathrm{ATP}}=\frac{D}{2(\mathrm{P} / \mathrm{O}) Q_{\mathrm{o}_{2}}+(\alpha-\mathrm{I}) \nu_{x}^{\prime}},
$$

where $Y_{\mathrm{ATP}}=(\mathrm{mg}$. dry mass $/$ mmole ATP), $\mathrm{D}=$ dilution rate (specific growth rate, $\mathrm{hr}^{-1}$ ), $\alpha=$ ATP synthesized by the substrate level phosphorylation per glucose consumed (mmole ATP/mmole glucose), $\nu_{x}^{\prime}=$ specific glucose consumption rate (mmole glucose/mg. bacterium hr).

The term $2(\mathrm{P} / \mathrm{O}) Q_{\mathrm{o}_{2}}$ implies the specific rate of production of ATP by the oxidative phosphorylation, whereas another term, $(\alpha-\mathrm{I}) \nu_{x}^{\prime}$ signifies the specific rate of production of ATP by the substrate level phosphorylation. The second term $(\alpha-1) \nu_{x}^{\prime}$ generally is insignificant compared with the first term, particularly in this strictly aerobic organism.

Table 2. Values of $Y_{A T P}$ (from equation (2)) for a glucose-limited chemostat culture of Azotobacter vinelandii

It was assumed that the ratio $\mathrm{P} / \mathrm{O}=\mathrm{I}$ :. $Y_{\mathrm{ATP}}$ from equation (2) was multiplied by 0.85 to be consistent with dry mass basis (see the text).

$\begin{array}{cccc}\begin{array}{c}\text { Dilution rate } \\ \left(\mathrm{hr}^{-1} \text { ) }\right.\end{array} & \begin{array}{c}Y_{\mathrm{ATP}} \\ \text { (mg. dry wt/ } \\ \text { mmole ATP) }\end{array} & \begin{array}{c}Y_{\overline{0}}^{\underline{X}} \\ \text { (mg. bacteria/ } \\ \text { mmole } \mathrm{O}_{2} \text { ) }\end{array} & \begin{array}{c}Y_{\overline{\mathbf{s}}}^{\underline{X}} \\ \text { (mg. bacteria/ } \\ \text { mg. glucose) }\end{array} \\ 0.1 & 0.425 & 1 \cdot 0 & 0.03 \\ 0.2 & 0.77 & 1.8 & 0.06 \\ 0.3 & 1.27 & 3.0 & 0.10\end{array}$

The $\mathrm{P} / \mathrm{O}$ ratio of Azotobacter vinelandii changes most likely if the branched electron transport pathway (Jones \& Redfearn, 1967) is acceptable. Here the $\mathrm{P} / \mathrm{O}$ ratio was assumed unity, referring to the data $(\mathrm{P} / \mathrm{O}=0.2$ to 0.8$)$ published by Tissières et al. (I957) and Hovenkamp (1959), because the previous data in vitro seemed to justify the assumption.

Thus, the value of $Y_{\mathrm{ATP}}$ is estimated approximately by the following equation,

$$
Y_{\text {ATP }}=\frac{D}{2 Q_{\mathrm{O}_{2}}} \text {. }
$$

The result of this calculation is shown in Table 2, in which the values of $Y_{\bar{S}}^{\frac{X}{S}}$ and $Y \frac{X}{\bar{o}}$ are cited from Fig. 2 and 3.

Although with many organisms the $Y_{\mathrm{ATP}}$ value was found to be approximately ro (Bauchop \& Elsden, I960; Stouthamer, 1962; Hadjipetrou et al. 1964), Hernandez \& Johnson (1967) pointed out the possibility that the value of $Y_{\text {ATP }}$ may become smaller than Io if some substances other than ATP are limiting the synthesis of cellular material. We therefore conclude that the value of $Y_{\text {ATP }}$ for Azotobacter vinelandii was remarkably small (Table 2) since, although they had an abundance of ATP, they lacked materials for growth in this glucose-limited environment. Thus the increase of $Y \frac{X}{S}$ found when the dilution rate was increased was accompanied by the increase of the value of $Y_{\mathrm{ATP}}$ (and $Y_{\frac{X}{0}}^{\underline{X}}$ ).

Thanks are due to M. Onodera, for his technical assistance. 


\section{REFERENCES}

Aiba, S., Nagai, S., Nishizawa, Y. \& Onodera, M. (1967). Energetic and nucleic analyses of a chemostatic culture of Azotobacter vinelandii. J. gen. appl. Microbiol. 13, 73.

BaIDYA, T. K. N., Webr, F. C. \& LILLY, M. D. (1967). The utilization of mixed sugars in continuous fermentation. Biotechnol. Bioeng. 9, 195.

Bauchop, T. \& ElSDEN, S. R. (1960). The growth of micro-organisms in relation to their energy supply. J. gen. Microbiol. 23, 457.

Hadjipetrou, L. P., Gerrits, J. P., Teulings, F. A. C. \& Stouthamer, A. H. (I964). Relation between energy production and growth of Aerobacter aerogenes. J. gen. Microbiol. 36, I39.

Herbert, D., Elsworth, R. \& Telling, R. C. (1956). The continuous culture of bacteria; a theoretical and experimental study. J. gen. Microbiol. 14, 601.

Hernandez, E. \& Johnson, M. J. (1967). Anaerobic growth yields of Aerobacter cloacae and Escherichia coli. J. Bact. 94, $99 \mathrm{I}$.

HovenKAMP, H. G. (1959). Oxidative phosphorylation in Azotobacter vinelandii. Biochim. biophys. Acta 34, 485 .

Jones, C. W. \& REDfEARn, E. R. (I967). The cytochrome system of Azotobacter vinelandii. Biochim. biophys. Acta 143, 340.

Parker, C. A. \& ScutT, P. B. (1960). The effect of oxygen on nitrogen fixation by Azotobacter. Biochim. biophys. Acta $\mathbf{3 8}, 230$.

PIRT, S. J. (1965). The maintenance energy of bacteria in growing cultures. Proc. Roy. Soc. Lond. B I63, 224.

Schulze, K. L. \& LIPE, R. S. (1964). Relationship between substrate concentration, growth rate, and respiration rate of Escherichia coli in continuous culture. Arch. Mikrobiol. 48, I.

SOMOGYI, M. (1952). Notes on sugar determination. J. biol. Chem. 195, 19.

Stouthamer, A. H. (1962). Energy production in Gluconobacter liquefaciens. Biochim. biophys. Acta $56,19$.

Tissières, A., Hovenkamp, H. G. \& Slater, E. C. (1957). The respiratory enzyme systems of Azotobacter vinelandii. Biochim. biophys. Acta 25, 336. 